\title{
Correction to: The Advanced Development Pathway of the RTS,S/ASO1 Vaccine
}

\section{Lorenz von Seidlein}

\section{Correction to:}

Chapter 13 in: Frédéric Ariey et al. (eds.), Malaria Control and Elimination, Methods in Molecular Biology, vol. 2013, https://doi.org/10.1007/978-1-4939-9550-9_13

This book was inadvertently published without updating the following corrections:

On p. 178, the word "more" in the sentence "The vaccine was more protective when children were vaccinated between 6 and 12 weeks than between 5 and 17 months of age, and a booster vaccination at 20 months provided added protection" has been replaced with "less". The sentence is updated as "The vaccine was less protective when children were vaccinated between 6 and 12 weeks than between 5 and 17 months of age, and a booster vaccination at 20 months provided added protection" in the revised version of the book.

On p. 179 , the numbers $38.5 \%$ (7.8 to 59.0 ) in Table 1 is replaced with $51.3 \%$ (47.5 to 54.9 )

The updated online version of this chapter can be found at https://doi.org/10.1007/978-1-4939-9550-9_13 